\title{
EL TESTAMENTO VITAL: UNA GENUINA MANIFESTACIÓN DE LA AUTONOMÍA DE LA VOLUNTAD
}

Sylvia Torres Morales de Ferreyros*

Recibido: 28.08 .2015

Aprobado: 10.09 .2015

\section{RESUMEN}

El presente artículo pretende abordar la importancia del respeto a la autonomía de la voluntad de las personas que desean dejar, en forma anticipada, -a través de los llamados Testamentos Vitales- directrices o instrucciones referidas a la aplicación o no de un tratamiento médico para su propio cuerpo, en caso de que en el futuro surgiera alguna situación que las incapacitara mentalmente a brindar algún tipo de consentimiento. El artículo plantea el siguiente cuestionamiento: si la persona puede consentir sobre los tratamientos médicos a seguir respecto de su propio cuerpo, ¿qué impide que dicho consentimiento lo manifieste por escrito y de manera anticipada para ser aceptado y, sobre todo, acatado en el futuro, en caso de que no pueda brindar su consentimiento por estar incapacitada mentalmente?

\section{ABSTRACT}

This article aims to address the importance of respecting a person's autonomy when he gives, in advance, -through the so-called End-of-Life Decision (Testamentos Vitales)- guidelines or instructions concerning the application, or not, of medical treatment to his own human body, should he lack the capacity to give such consent in the future. The article raises the following questions: whether or not the person can consent on the medical treatment to be followed regarding his own human body, what prevents him from expressing such consent in writing and in advance, its acceptance and, above all, whether or not his decision will actually be observed in the future when he cannot give his consent due to mental disability.

\section{PALABRAS CLAVES}

Autonomía de la Voluntad. Libertad. Testamento Vital. Directrices Anticipadas de Salud. Ética.

\section{KEY WORDS}

Freedom of choice. Liberty. Living Will. Advance Health care directives. Éthics.

\footnotetext{
* Abogada. Con estudios concluidos en la Maestría en Derecho Civil con mención en Familia por la Universidad Femenina del Sagrado Corazón - UNIFE. Ha sido Miembro del Instituto de la Familia de la UNIFE y de la Cátedra UNIFÉ de Bioética y Biojurídica, además de Jefa del departamento de Ciencias Jurídicas de la misma Universidad. Actualmente es socia del Estudio Torres y Torres Lara Abogados y forma parte del Área de Responsabilidad Social de dicha institución. Correo electrónico: storresm@tytl.com.pe.
} 


\section{INTRODUCCIÓN}

Es muy común que los seres humanos tiendan a reflexionar sobre el futuro e, indefectiblemente, sobre la vida que algún día concluirá; por ello las personas -en su afán previsor- suelen pensar en cómo tendría que quedar distribuido el patrimonio acumulado e incrementado durante toda una vida. Nuestra legislación trata muy bien este tema en lo que se refiere a la institución sucesoria, estableciendo una suerte de prelación respecto a las personas -herederos- que tendrán un derecho legítimo sobre dicho patrimonio por tratarse de herederos forzosos o herederos legales. Sin embargo, nuestra normatividad también prevé la posibilidad de que la persona haciendo uso de su legítima autonomía redacte un testamento, es decir una manifestación de última voluntad donde señale -sin perjudicar a los herederos forzosos- cómo desea que se distribuya por ejemplo, su tercio de libre disposición. Todo ello se encuentra debidamente regulado por el Libro IV del Código Civil Peruano. Sin embargo, esta manifestación de deseo se refiere única y exclusivamente a los bienes patrimoniales, por lo que nos preguntamos, ¿podría además, la persona, regular su voluntad respecto al tratamiento de su propio cuerpo en caso que quedara incapacitada de tal forma que no pudiera expresar ella misma sus deseos? Aquí, estamos hablando de una voluntad que se haría efectiva no cuando la persona muera (como es el caso del tes- tamento patrimonial: muere la persona y luego de un procedimiento, se reparten los bienes entre los herederos) sino en el momento en que, pese a estar con vida, no puede ejercer su derecho a elegir por encontrarse incapacitado; en pocas palabras, estamos hablando no de la última voluntad sino más bien, de la penúltima voluntad del ser humano. ${ }^{1}$

El presente artículo pretende abordar esta singular situación que, poco a poco, se va haciendo más conocida en los demás países del mundo pero que en Perú aún no ha sido tomada con la importancia debida por lo que no ha generado, pese a importantes esfuerzos, una adecuada normatividad al respecto.

\section{El Testamento Vital: Defi- NICIÓN}

El Testamento Vital, que proviene del término inglés " $\mathrm{Li}$ ving Will" es también conocido como "declaración de voluntades anticipadas", "autotutela", "autoprotección", entre otros. Sin embargo, más allá del nombre, todos ellos dejan escapar en la simple lectura de su denominación, un deseo de la propia persona, es decir, un deseo de ejercer autónomamente una voluntad.

El profesor José Abellán Salort, nos brinda un acercamiento muy claro a lo que significa el principio de la autonomía de la persona al señalar que..."nace como contraposición al imperante paternalista médico. Se trata de proponer como punto de partida de toda decisión, el respeto de la decisión personal del paciente, el respeto de sus preferencias, de su libertad de elección, de su libre arbitrio, que son los principales elementos-guía para alcanzar una decisión" (Abellán Salort, 2008, p. 18).

Siguiendo esa línea de pensamiento, cuando hablamos del Testamento Vital, nos estamos refiriendo a un documento (no a una mera declaración oral) donde se manifiestan voluntades referidas al tratamiento del cuerpo humano, en caso de que ocurra una situación penosa, ya sea producto de una enfermedad o de un accidente, en que la persona quede incapacitada mentalmente para poder manifestar ella misma sus deseos en relación, reiteramos, a su propio cuerpo. En dicho documento, por tanto, la persona en plena capacidad mental, manifiesta anticipadamente, las instrucciones de cómo debería actuar la familia y los profesionales de la salud respecto de ella. Al referirse a la voluntad anticipada, Gabriel García Colorado sostiene que ésta..."constituye la mejor expresión de autonomía y competencia personal en búsqueda de una muerte digna. Se origina por el desplazamiento del principio de autonomía sobre el de beneficencia, de ahí que cada vez con mayor intensidad los pacientes con ejercicio pleno de su autonomía demanden una mayor participación en la toma de decisiones acerca de su estado de salud y de los procedimientos sugeridos por

Frase acuñada por la profesora y jurista Rosalía Mejía Rosasco, autora del libro: “Estipulaciones de autotutela para la propia incapacidad: la penúltima voluntad.” (2009). Editorial Grijley. Lima. 
el equipo de salud." (García Colorado, Gabriel y otros, 2008, p. 51).

Esta manifestación de voluntad alcanza incluso una mayor relevancia en el caso de personas en las que científica y médicamente se puede anticipar un paulatino deterioro mental, lo que hará imposible la posibilidad de poder adoptar, cuando la enfermedad esté plenamente manifestada, decisiones relevantes; es el caso, por ejemplo, de la demencia senil o de la muy conocida enfermedad del Alzheimer. Por tanto, no debemos cerrar los ojos ante una realidad, pues ..."se sabe que las enfermedades demenciales afectan a más de 20 millones de personas en el planeta; y las proyecciones epidemiológicas indican que esta cifra se multiplicará muchas veces dentro de los próximos años, conjuntamente con la población de adultos mayores" (Osada Liy, 2009, p. 199). Dichas enfermedades presentan varias etapas, por lo que, de ser detectadas en una etapa inicial, el paciente se encuentra aún capacitado mentalmente para manifestar deseos válidos, es decir, anticiparse a una situación inminente $\mathrm{y}$, por tanto, dejar las "instrucciones" que considere pertinentes.
Por otro lado, al hablar del Testamento Vital, no podemos pasar por alto la figura del llamado "Consentimiento Informado"2 (también denominado "derecho de los pacientes" o "derecho de los enfermos"), que es el derecho de toda persona a ser debidamente informada por el profesional de la salud, respecto a la dolencia que le aqueja a fin de poder brindar su consentimiento (valga la redundancia) para un eventual tratamiento médico (ya sea la realización o no de terapias médicas, intervenciones quirúrgicas, etc.) Este derecho, es pues, una manifestación más de la autonomía de la voluntad y se encuentra relacionado directamente con el derecho fundamental a la integridad personal, que se encuentra regulado en nuestra Carta Magna, en su artículo segundo.

En ese sentido, debemos preguntarnos: si es legal, válida y legítima la manifestación de voluntad a través del consentimiento informado, para que el profesional de la salud actúe de una u otra forma respecto al tratamiento médico de la persona por el solo pedido de la misma, ¿por qué no regular legalmente dicho mismo pedido, pero de modo anticipado, a través del llamado Testamento Vital? La única diferencia es que el cumplimiento del deseo de la persona se ejecutará no en el momento actual sino que se traslada al futuro (en caso de presentarse la dolencia que lo incapacite mentalmente a brindar este consentimiento); sin embargo, se trata de la misma persona quien autónomamente toma una decisión en un momento en el que se encuentra en plena capacidad mental para hacerlo.

\section{El Testamento Vital: Ante- CEDENTES HISTÓRICOS}

\subsection{EL PUNTO DE PARTIDA.}

La profesora Rosalía Mejía Rosasco, en su interesante ya mencionada obra: "Estipulaciones de Autotutela para la propia incapacidad: La penúltima voluntad" (Mejía Rosasco, 2009, p. 150), nos presenta como la primera evidencia que se encuentra en la historia -que puede ser considerada como el punto de partida de la validez de las declaraciones anticipadas-, el caso del ciudadano ruso, de origen finlandés, Ivon Cnimzo, quien conocía que tenía -en etapa inicial- una enfermedad mental degenerativa que lo llevaría indefectiblemente a la locura (tenía tal convicción ya que los médicos le habían asegurado que se trataba de una dolencia de tipo hereditaria y sus ascendientes

\footnotetext{
La figura del Consentimiento Informado, además de encontrarse sustentada en las normas que protegen la integridad de la personas, tiene su lugar especial en la Ley General de Salud, Ley 26842, norma que en sus artículos 4 y 15 acápite g) lo regula de la siguiente manera: "4. Ninguna persona puede ser sometida a tratamiento médico o quirúrgico, sin su consentimiento previo o el de la persona llamada legalmente a darlo....salvo el caso de las intervenciones de emergencia". "15. Tiene derecho a que se le dé en términos comprensibles información completa y continuada sobre su proceso, incluyendo el diagnóstico, pronóstico y alternativas de tratamiento, así como los riesgos, contraindicaciones, precauciones y advertencias de los medicamentos que se le prescriban y administren".

Pero, además de un imperativo legal, también se trata de un imperativo moral, pues así lo reconoce el propio Código de Ética del Colegio Médico del Perú, cuando en su artículo 63 inciso e) señala que “(...) El paciente tiene derecho a: (...) e) Aceptar o rechazar un procedimiento o tratamiento después de haber sido adecuadamente informado a revocar su decisión en cualquier momento, sin obligación de expresión de causa."
} 
la habían padecido). Así, en el año 1927 esta "certeza" de un inminente futuro deterioro mental lo llevó, una vez que cumplió la mayoría de edad, a autorizar un documento privado en el que nombraba a un tutor designado por él mismo a fin que cumpliera con sus instrucciones cuando la enfermedad llegara, hecho que sucedió cuando Cnimzo cumplió los 24 años de edad. El caso se llevó a la justicia rusa que debatió la posibilidad de que una persona -mayor de edad- pueda o no nombrar a su propio tutor para ejercer las funciones propias de este encargo a futuro. Finalmente, se decidió reconocer la plena validez del documento firmado por Cnimzo y su voluntad fue cumplida.

\subsection{LA HISTORIA NORTEAMERICA- NA: TRES CASOS EMBLEMÁTICOS.}

Por otro lado, resulta importante señalar que, si bien el caso Cnimzo fue el punto de partida para el inicio de la validación de las directrices anticipadas, no podemos dejar pasar la historia norteamericana pues, hoy en día, Estados Unidos es uno de los países en donde -para bien o en algunos casos para mal- la autonomía de la voluntad ha cobrado una especial importancia.

Es así como en USA, la experiencia con los "Living Will", que significa, "advance health care directives", es decir "directivas anticipadas de salud" (y que luego derivó al término castellano "testamento vital", pues engloba dos aspectos: documento de manifestación de voluntades y ejecución en vida), se inicia en el año 1967, en una reunión de la Sociedad Americana de Eutanasia. En dicha reunión se lanza por primera vez la idea de un documento escrito al que llamaron "Living will", mediante el cual el paciente expresa su deseo de ser tratado en caso que no pudiera decidir por sí mismo. Si bien es cierto, la idea tuvo en ese momento muy poca aceptación, fue aproximadamente 11 años después, en 1976, cuando a raíz del caso Karen Ann Quinlan, el Estado de California aprobó la primera norma que legaliza los testamentos vitales y abre el proceso a su reconocimiento jurídico generalizado.

\subsubsection{Caso Karen Ann Quintan.}

Karen Ann Quinlan era una joven norteamericana que buscaba constantemente una bella apariencia, lo que la llevó a efectuar diversas dietas para bajar y mantener el que consideraba un peso ideal. El 15 de abril del año 1975, cuando tenía sólo 21 años de edad y 50 kilogramos de peso, asistió a una fiesta habiendo comido en un periodo anterior de 48 horas, tan solo dos rebanadas de pan. En dicha fiesta ingirió mucho alcohol y drogas; luego de ello se sintió mareada y sus amigos la llevaron a descansar, tiempo después la encontraron inconsciente y sin rasgos de respiración. El diagnóstico de los médicos fue que se quedó dormida o inconsciente y que se ahogó con su vómito. La falta de respiración prolongada le generó un daño cerebral, hecho que la dejó en un inminente estado vegetati$\mathrm{vo}^{3}$, todo ello producido por la poca comida ingerida y la combinación del alcohol y drogas. Karen "vivía" desde entonces conectada a un respirador artificial y se le suministraban los alimentos a través de una sonda nasogástrica, por lo que los padres de ella solicitaron al centro hospitalario la desconexión del aparato artificial, pero el hospital se negó. Los padres llevaron el caso a la Corte Suprema de New Jersey en el año 1976, oportunidad en que la Corte falló a favor de los padres y se procedió a retirar el aparato de respiración artificial, sin embargo Karen continuó respirando en forma espontánea, por lo que continuó siendo alimentada a través de la sonda durante 9 años más. En el año 1985, murió producto de una neumonía; en ese momento tenía 31 años y pesaba 36 kilogramos. $^{4}$

3 Para la Academia Pontificia de la Vida, el individuo en un estado vegetativo "...no tiene capacidad de respuesta. Actualmente se define como una condición caracterizada por: estado de vigilia, alternancia de ciclos de sueños y vigilia, ausencia aparente de conciencia de sí y del ambiente circunstante, falta de respuestas de comportamiento de estímulos al medio ambiente, mantenimiento de las funciones autonómicas y de otras funciones cerebrales." Citado por el profesor español José Serrano Ruiz-Calderón, en su artículo: "La alimentación artificial de personas en situación de fuerte dependencia. Nota sobre un debate jurídico estadounidense”. En: www.revistas.unam/mx.index.php/bmd/ article/download/23383/22096

4 Se consultó la siguiente página en internet: http://eticajarrio.blogspot.com/2012/07/un-poco-de-historia-el-caso-deann.html. Blog del Comité de Ética del Área I de Asturias y Hospital de Jarrio. Un espacio público para la reflexión de principios y valores. 
La vida y muerte de Karen Ann Quinlan se convirtió para los Estados Unidos de Norteamérica, en un caso emblemático debido a que la sentencia del Tribunal analizaba aspectos muy importantes como:

a) El derecho a una muerte digna;

b) La terrible disyuntiva de mantener o no con vida a una persona en estado vegetal;

c) El dilema ético que significaba la tecnología del soporte vital;

d) El problema del llamado "encarnizamiento terapéutico" y; finalmente

e) La importante recomendación que hizo la Corte respecto de la necesidad de que se creasen en los hospitales los llamados "Comités de Ética", a efectos de poder analizar y lidiar con estos casos que plantean problemas éticos críticos $y$ reales.

\subsubsection{Caso Nancy Cruzan.}

Otra situación muy interesante -que también generó una conmoción en la sociedad americana y, en esta oportunidad, más aún, ya que permitió que se empezara a pensar en cuál habría sido la voluntad del paciente si hubiera podido decidir-, fue el caso de la joven Nancy Cruzan.

En el año 1983, Nancy Cruzan, una joven de 24 años de edad, perdió el control de su automóvil produciéndose un terrible accidente que la impulsó fuera de su vehículo deján- dola boca a bajo en un estanque con agua. Pese a que los paramédicos hicieron todo lo posible y lograron reanimarla, quedó inconsciente y luego de dos semanas, ingresó en lo que se denomina "estado vegetativo persistente", señalando los médicos que producto de la falta de oxígeno en un periodo prolongado de tiempo, se había generado daño cerebral irreversible. Pese a que no "vivía" con un respirador artificial pues su respiración era espontánea, no le era posible pasar los alimentos en forma natural, por lo que era alimentada a través de tubos y sondas. Los familiares de Nancy no veían avance ni mejora alguna, por lo que en el año 1987, cuatro años después del penoso accidente, perdieron totalmente las esperanzas de una recuperación y solicitaron expresamente al hospital que retirara el aparato que alimentaba a Nancy. El hospital se negó señalando que precisaban de una orden judicial para ello pues lo solicitado por los padres constituía dejar morir a un paciente por inanición.

Este caso, a diferencia del analizado anteriormente (Caso Quinlan), tuvo alcances superiores pues fue el primero en llegar en apelación a la Corte Suprema de los de Estados Unidos $^{5}$. El juez de primera instancia falló en favor de los padres considerando que éstos tenían la representación y legitimidad suficiente para decidir por su hija. Además, los padres habían señalado durante todo el proceso que, en conversaciones sostenidas entre su hija y su hermano y una amiga, ella habría señalado que de producirse un hecho de esta naturaleza, rechazaría los tratamientos que la mantuvieran con vida alargando su agonía sin esperanza de recuperación. El juez consideró que la paciente - a través de sus padres- tenía el derecho a rechazar los tratamientos no deseados. Sin embargo, la decisión de este juez fue apelada por el Fiscal General del Estado y subió a la Corte Suprema de USA, la misma que rechazó la petición de los padres aduciendo que las manifestaciones que habría efectuado Nancy a su hermano y amiga, sobre el supuesto rechazo a mantenerla con vida, no habrían sido, claras y convincentes evidencias dadas por adelantado, por lo que no estaba constitucionalmente permitido que los padres decidieran por el futuro de su hija y que el Estado no podría ser cómplice de un suicidio (Arbe Ochandiano, 2011, p. 39-40).

A pesar de ello, los padres de Nancy continuaron luchando y en el año 1990, lograron conseguir un fallo a su favor al haber aportado evidencias más fehacientes del verdadero deseo de su hija. Así, el 15 de diciembre de 1990, 7 años después de haber sufrido el accidente, el tubo de alimentación de Nancy fue removido muriendo 11 días después.

Este caso fue de mucha trascendencia pues, por primera vez, la Corte Suprema de los Estados Unidos se pronunció sobre la problemática de los pacientes incapaces, asimismo

5 El caso Quinlan fue decidido en apelación a nivel de la Corte Suprema del Estado de New Jersey. 
se sentaron las bases del consentimiento informado como manifestación del principio de autonomía en defensa de la libertad.

Definitivamente, los casos de Karen Ann Quinlan y de Nancy Cruzan permitieron a la sociedad americana analizar la problemática de los pacientes en estado de incapacidad, que no pueden manifestar su voluntad por sí mismos, y que se convirtieron en el impulso que se necesitaba para que hoy en día los testamentos vitales sean legales $y$, legítimamente aceptados en los Estados Unidos, como una válida manifestación de la autonomía del paciente a rechazar tratamientos o aceptarlos.

\subsubsection{Caso Terry Schiavo ${ }^{6}$.}

Un caso más reciente pero también muy emblemático en los Estados Unidos, -por la conmoción que nuevamente causó al plantearse, por un lado, el dilema ético de mantener con vida artificial a una persona en un estado vegetativo persistente y, por otro, la falta de conocimiento veraz de la voluntad del paciente por estar incapacitada mentalmente-, fue la vida y muerte de Terri Schiavo.

Theresa Marie Schindler (conocida públicamente como Terri Schiavo), nació en Pensilvania (USA) en el año 1963. En 1984, contrae matrimonio con Michael Schiavo. No procrearon hijos. Cuando Terri tenía 27 años de edad, producto de sus constantes acciones por el deseo incesante de adelgazar, que la habían llevado incluso a alimentarse por varios días con solo té helado adelgazante, le generaron un paro cardíaco. Los médicos señalaron que el paro cardíaco había sido consecuencia de un déficit de potasio en el organismo de Terri. La falta de oxígeno en el cerebro antes de haber sido auxiliada médicamente (aproximadamente una hora y media) le causó un profundo daño cerebral $\mathrm{y}$, posteriormente, tras unos meses en estado de coma, ingresó a un estado vegetativo persistente. Años después se inició una batalla legal entre el esposo de Terri, quien deseaba que se le retiraran los aparatos que la mantenían con vida, y los padres de Terri, quienes mantenían la esperanza de la futura recuperación de su hija, debido a que Terri les sonreía, movía la cabeza y daba señales de estar consciente de todo lo que sucedía.

El caso Terri Schiavo llegó hasta la Corte Suprema y ésta decidió finalmente que, pese a que Terri no había redactado un testamento vital, indicando sus deseos respecto al tratamiento médico de su cuerpo, había informaciones que hacían presumir que Terri no hubiese deseado que se le aplicaran medidas extraordinarias para mantenerla con vida. La oposición de los padres, seguida de nuevos recursos, sólo logró retrasar un tiempo más la decisión final: el retiro de la sonda por la cual se alimentaba Terri durante 15 largos años. Trece días después del retiro de este soporte vital, Terri Schiavo falleció por falta de alimento.

Esta decisión comenzó una gran polémica y debate a nivel mundial. Pero más allá del tema de lo procedente o no de suspender la alimentación de un ser humano, es decir, provocar su muerte por inanición, está el cuestionamiento que nos interesa, específicamente para el caso del presente artículo, de si la decisión adoptada por la Corte Suprema era lo que Terri Schiavo hubiese deseado o, por el contrario, nos queda la duda (y quedará siempre) si habría querido que continuaran luchando (como lo querían y demandaban sus padres) para retornarla a un estado normal. La decisión fue basada en supuestos, no en certezas. Sólo hubiera existido una certeza absoluta si Terri Schaivo hubiera redactado y suscrito un testamento vital.

\subsection{El caso español.}

España es uno de los principales países del mundo en que el tema de la autonomía de la voluntad está largamente desarrollado y es de importancia prioritaria. Como dato importante podemos señalar que en el año 2000, en las provincias de Cataluña y de Galicia, se promulgó por primera vez una legislación orientada a normar las llamadas "directivas anticipadas" y, dos años después, se recogió a nivel nacional en la Ley de Autonomía del Paciente ${ }^{7}$.

6 Datos obtenidos de internet: http://www.investigacionyciencia.es/blogs/psicologia-y-neurociencia/63/posts/la-largamuerte-de-terri-schiavo-12420.

7 La propia ley citada, trata varios aspectos que circundan la vida del paciente como: información sanitaria, el consentimiento informado, el derecho a la intimidad, la historia clínica, y otros, señala en su exposición de motivos que dicha ley 
Consideramos importante citar lo que dicha Ley, en su artículo 11 establece, al normar las "Instrucciones Previas":

Por el documento de instrucciones previas, una persona mayor de edad, capaz y libre, manifiesta anticipadamente su voluntad, con objeto de que ésta se cumpla en el momento en que llegue a situaciones en cuyas circunstancias no sea capaz de expresarlos personalmente, sobre los cuidados y el tratamiento de su salud o, una vez llegado el fallecimiento, sobre el destino de su cuerpo o de los órganos del mismo. El otorgante del documento puede designar, además, un representante para que, llegado el caso, sirva como interlocutor suyo con el médico o el equipo sanitario para procurar el cumplimiento de las instrucciones previas."

Queda pues claro que la normatividad española permite al paciente mayor de edad con capacidad, redactar un documento dejando expresos deseos, que deben ser respetados -y la ley le da esa garantía- respecto a su tratamiento médico en caso de que en el futuro no pueda manifestar, por sí mismo, sus deseos.

\section{El Testamento Vital: Líml- TES LEGALES Y ÉTICOS}

Al hablar de límites al Testamento Vital, primero debemos plantear la pregunta de si podemos poner límites a la autonomía de la voluntad, siendo la respuesta afirmativa. No todo lo que el ser humano desea hacer, lo puede hacer.

El Dr. Ronald Cárdenas Krenz, experto en Bioética y Biojurídica, señala sobre el particular, lo siguiente: ..."consideramos que la autonomía de la voluntad tiene ... entre sus límites en general, el respeto a la vida (derecho fundamental y sustento del resto de derechos), la consideración kantiana del hombre como fin (principio de autotelia), el principio del interés superior del niño (reiterado ampliamente en diversas sentencias del Tribunal Constitucional), el principio de que no hay libertad sin responsabilidad, el orden público y las buenas costumbres, la razón y el sentido común, los derechos fundamentales, el principio de que la ley no ampara el abuso del derecho, los principios de la Bioética, el ordenamiento jurídico en general (que incluye el cumplimiento de los requisitos de validez del acto jurídico, la inexistencia de vicios de la voluntad, etc.), la moral, la propia voluntad en general, la aplicación del principio de simetría, etc."8
En el caso específico de los testamentos vitales, materia de nuestro artículo, debemos señalar que sus límites están dados fundamentalmente por el ordenamiento jurídico de cada país. Así, cuando hablamos de dichos límites, debemos pensar en cuáles son los alcances que se le puede dar al Testamento Vital, es decir, cuáles son los deseos del paciente que, legalmente, está permitido respetar.

Por ejemplo, en legislaciones donde se acepta el suicidio asistido (Suiza) y la eutanasia (Holanda y Bélgica), debemos señalar que los límites son muy pocos, pues el paciente puede, incluso dejar escrito en un testamento vital de que lo "ayuden a morir", es decir, una situación activa para eliminar una vida.

Ahora bien, concentrémonos en nuestra realidad. En el Perú tenemos normas expresas que prohíben la eutanasia y el suicidio asistido. Así, los artículos 112 y 113 del Código Penal Peruano señalan lo siguiente al describir los tipos penales: Homicidio piadoso $0^{9}$ e Instigación o ayuda al suicidio:
"Artículo 112.- El que, por piedad, mata a un enfermo incurable que le solicita de manera expresa y conscien- te para poner fin a sus in- tolerables dolores, será re-

"refuerza y da un trato especial al derecho a la autonomía del paciente. En particular, merece mención especial la regulación sobre instrucciones previas que contempla (...) los deseos del paciente expresados con anterioridad dentro del ámbito del consentimiento informado" (el resaltado es nuestro).

8 Expresado en la Ponencia "¿Qué tan autónoma es la autonomía de la voluntad? Consideraciones a partir de algunas interesantes sentencias del Tribunal Constitucional peruano", presentada en la ciudad de Córdoba - Argentina con motivo de su incorporación como Miembro de Número de la Academia Nacional de Córdoba. Año 2015.

9 En nuestra legislación no se habla de "eutanasia" sino de "Homicidio por piedad" u "Homicidio piadoso". Nótese que el sujeto activo de dicho delito puede ser cualquier persona; en el caso de la eutanasia, el sujeto activo es el profesional de la salud. Por ello, nuestra legislación, al regular el tipo penal del artículo 112, abarca no sólo a la eutanasia sino a todo acto efectuado por cualquier persona dirigido a matar por razones de índole piadoso. 
primido con pena privativa de la libertad no mayor de tres años".

"Artículo 113.- El que instiga a otro a cometer suicidio o lo ayuda a cometerlo, será reprimido, si el suicidio se ha consumado o intentado, con pena privativa de la libertad no menor de uno ni mayor de cuatro años (...)".

En esa línea de pensamiento, queda evidenciado que, de regularse el testamento vital en nuestro país, la persona no podrá solicitar en dicho documento, por ejemplo, que si queda en estado comatoso, se le aplique una inyección de cloruro de potasio para generarle un paro cardiaco y provocarle la muerte. Ello, no está permitido por nuestras normas.

Ahora bien, sí podría, por el contrario, manifestarse en contra del llamado encarnizamiento terapéutico, es decir el deseo denodado de mantener con vida a un paciente realizando acciones desproporcionadas y heroicas que sólo alargan la agonía del mismo, sin ninguna esperanza de recuperación. En otras palabras, es aplicar artificialmente la "distanasia"10, es decir, actuar de tal forma que se ponga distancia entre la vida y la muerte. Ello, va en contra de la llamada "ortotanasia" (término que proviene de los vocablos griegos: orto=correcto; thánatos= muerte), es decir de la "muerte en el momento correcto". Pese a que la muerte ya llegó en forma natural "en el momento correcto"), se mantiene al paciente con vida a través de soportes artificiales.

Una cuestión importante a determinar es, precisamente, esa línea delgada que determina si el paciente tiene o no posibilidades de recuperación y cuándo, por tanto, se está cayendo en el citado "encarnizamiento terapéutico". La Dra. María Luisa Pfeiffer, miembro de la Asociación Argentina de Investigaciones Éticas, señala que "se considera apropiado retirar el soporte vital: cuando no haya evidencia de la efectividad buscada y se presuma que tampoco se obtendrá en futuro; cuando mantener ese soporte sólo signifique mantener y prolongar un cuadro de inconciencia permanente e irreversible; cuando el sufrimiento sea inevitable y desproporcionado al beneficio médico esperado, cuando se conozca fehacientemente la voluntad del paciente, cuando la irreversibilidad del cuadro permita pensar que continuar no redundará en el mejor beneficio del paciente." (El resaltado es nuestro) (Pfeiffer, 2008, p. 76).

Es cierto que la decisión del retiro del soporte vital es sumamente delicada y difícil, y en realidad, sólo los profesionales de la salud son los llamados a señalar a la familia cuándo debería hacerse; por ello, en algunas ocasiones es importante que el centro de salud cuente con un Comité de Ética en biomedicina, lo que implica la existencia de "un grupo de personas que se constituye con la misión de deliberar sobre la modalidad de determinadas decisiones 0 cursos de acción, bien sea en la práctica clínica, en la investigación científica o en la gestión de los recursos sanitarios disponibles." "11 Son, pues, un importante apoyo para dilucidar y decidir respecto de dilemas éticos en la medicina.

Por otro lado, resulta importante conocer la posición de la Iglesia Católica por ser la religión preponderante en nuestro país. Esta se manifiesta en contra del encarnizamiento terapéutico y a favor del respeto a la ortotanasia. Así, en el Catecismo de la Iglesia Católica se señala lo siguiente:

"Aquéllos cuya vida se en-

10 El Dr. Patrick Wagner Grau, Presidente de la Academia Nacional de Medicina del Perú, concedió una entrevista al Diario El Comercio en el año 2005, tocando el tema de la distanasia con ocasión de la muerte del Papa Juan Pablo II. En dicha entrevista señaló: “Ese es todo un tema. Nosotros no permitimos el uso de la eutanasia, que es la supresión de la vida; pero tampoco permitimos la distanasia, que es el encarnizamiento terapéutico para prolongar la vida, rebajando muchas veces al ser humano, en su dignidad, y convirtiéndolo en objeto con fines terapéuticos o de investigación. Yo creo que en el caso del Papa ha habido una práctica de distanasia. Un extremo tan inhumano como la eutanasia. Por eso hoy día la bioética ha definido un término medio al que ha llamado "ortotanasia", que es la muerte a su debido momento, la muerte natural, conservando la dignidad del agónico. Acuérdese que la palabra "agonía” viene del griego y significa lucha, combate. Es la lucha por la vida hasta que uno muere".

11 J.J. Ferrer. Citado por José Carlos Bermejo y Rosa María Belda (Bermejo, José Carlos y Belda, Rosa María, 2006, p 100). 
bilitada tienen derecho a un respeto esencial: las personas enfermas o disminuidas deben ser atendidas para que lleven una vida tan normal como sea posible. Cualesquiera que sean los motivos y los medios, la eutanasia directa consiste en poner fin a la vida de personas disminuidas, enfermas o moribundas. Es moralmente inaceptable. Por tanto, una acción o una omisión que, de suyo o en la intención, provoca la muerte para suprimir el dolor, constituye un homicidio gravemente contrario a la dignidad de la persona humana y al respeto del Dios vivo, su Creador. El error de juicio en el que se puede haber caído de buena fe no cambia la naturaleza de este acto homicida, que se ha de rechazar y excluir siempre.

La interrupción de tratamientos médicos onerosos, peligrosos, extraordinarios o desproporcionados a los resultados puede ser legítima. Interrumpir estos tratamientos es rechazar el "encarnizamiento terapéutico". Con esto no se pretende provocar la muerte; se acepta no poder impedirla. Las decisiones pueden ser tomadas por el paciente, si para ello tiene competencia y capacidad o, sino por los que tienen los derechos legales, respetando siempre la voluntad razonable y los intereses legítimos del paciente. ${ }^{12}$ (El resaltado es nuestro).

Aunque la muerte se considere inminente, los cuidados ordinarios debidos a una persona enferma no pueden ser legítimamente interrumpidos. El uso de analgésicos para aliviar los sufrimientos del moribundo, incluso con riesgo de abreviar sus días, puede ser moralmente conforme a la dignidad humana si la muerte no es pretendida, ni como fin ni como medio, sino solamente prevista y tolerada como inevitable. Los cuidados paliativos constituyen una forma privilegiada de la caridad desinteresada. Por esta razón deben ser alentados."13

Queda claro entonces que la Iglesia Católica (Torres Morales, 2008, p. 33-35):

1) No acepta bajo ningún concepto la llamada "Eutanasia Directa" o "Eutanasia Activa", es decir, aquella acción tendente a suprimir en forma anticipada la vida de un enfermo. La Iglesia llega a calificar esta supresión como un "homicidio". El escudarse en el hecho de "no querer ver sufrir al ser querido" o en que "hay que respetar su decisión de morir con dignidad" no resta -de forma alguna- al acto, su verdadera naturaleza: un acto inmoral.
2) Rechaza el llamado "encarnizamiento terapéutico" pues lo relaciona directamente con la distanasia que se aplica al contar con la esperanza remota de que el enfermo mejore o que la ciencia médica avance de tal forma que la dolencia pueda ser revertida. Para ello, muchas veces, familiares, llevados por un legítimo deseo de mantener vivo a su ser querido, aceptan que se les apliquen tratamientos extraordinarios y heroicos que, lejos de aliviar el dolor del paciente, producen simplemente un alargamiento innecesario y cruel de su agonía.

La Iglesia está en contra del "encarnizamiento terapéutico" y más bien acepta la llamada "ortotanasia", es decir, acepta que la muerte ya está llegando y, por tanto, reconoce no poder impedirla. En ese caso, la Iglesia puede aceptar como ella misma lo señala- la interrupción de tratamientos médicos onerosos, peligrosos, extraordinarios o desproporcionados a los resultados esperados; en pocas palabras, acepta que la enfermedad ha ganado la batalla y que debemos dejar de luchar ante la inminente decisión de Dios.

3) Acepta que se respete la voluntad del paciente que está en condiciones de ma-

12 Obsérvese en este último párrafo la importancia que brinda la Iglesia Católica al deseo del paciente competente y capaz y al respeto de su voluntad y de sus legítimos intereses.

13 Catecismo de la Iglesia Católica. Quinto mandamiento. El respeto por la vida humana. La eutanasia. Acápites 2276, 2277, 2278 y 2279.(1992). Segunda Edición. Asociación de Editores del Catecismo. España. p. 501. 
nifestarla, siempre y cuando esta voluntad no vaya en contra de los parámetros morales y legales. Por ejemplo, un paciente válidamente podría optar por no aceptar un tratamiento de quimioterapia ${ }^{14}$ para tratar el cáncer que lo aqueja, pero, de ninguna manera, podría solicitar que se le aplique una solución química que le genere un infarto y con ello, su muerte. En estos ejemplos citados se puede observar la clara diferencia entre "dejar morir" y "hacer morir".

4) Se muestra plenamente a favor de los llamados "cuidados paliativos", que significan suministrar al paciente todos aquellos medios que signifiquen ayudarlo a sobrellevar la enfermedad sin dolor, es decir, menguar de alguna forma los sufrimientos que le aquejan producto de su enfermedad.

\section{Regulación del Testamento Vital EN NUESTRO País}

Debemos señalar que, pese a algunos intentos por regular la validación del Testamento Vital o directivas anticipadas en nuestro país, hasta el momento no es una prioridad en la agenda de nuestros legisladores.

Hoy en día, si una persona dejara por escrito su deseo expreso respecto al tratamiento médico de su cuerpo, no se podría, de forma alguna, alegar ante un Tribunal Peruano, la exigencia del cumplimiento de dicha voluntad; quedaría en la decisión de la familia actuar de una u otra forma.

Como hemos mencionado en el punto II del presente artículo, la Ley General de Salud regula el llamado consentimiento informado; sin embargo, dicha manifestación de voluntad debe ser otorgada en tiempo actual por el propio paciente $y$, en modo alguno podría afirmarse o tener la certeza de que un tribunal aceptaría válidamente el argumento de que dicha voluntad puede trascender en el futuro y por un hecho incierto. Esta falta de certidumbre "no ayuda a los pacientes, quienes quisieran tener la confianza que sus deseos serán respetados, como así tampoco a los doctores, quienes muy a menudo no saben cuál es la decisión correcta a tomar, tanto desde el punto de vista ético como legal." (Durante, 2012, 268)

No contamos, por tanto, con una norma expresa como sí lo hemos observado, por ejemplo en la legislación española a través de su Ley de Autonomía del Paciente (específicamente su artículo 11 , citado en el acápite 2.3 del presente trabajo).

Ahora bien, debemos admitir, que, no obstante lo señalado anteriormente, existe cierto avance en nuestra legislación respecto a este tema. Es así como la Ley 29633, promulgada el 16 de diciembre del año 2010, fortalece la tutela del incapaz o adulto mayor mediante una serie de modificaciones al articulado de nuestro código civil. Una de las modificaciones fue la de incorporar el artículo 568-A al Código Civil con el siguiente texto:

"Artículo 568-A.- Facultad para nombrar su propio curador.- Toda persona adulta mayor con capacidad plena de ejercicio de sus derechos civiles puede nombrar a su curador, curadores o curadores sustitutos por escritura pública con la presencia de dos (2) testigos, en previsión de ser declarado judicialmente interdicto en el futuro, inscribiendo dicho acto en el Registro Personal de la Superintendencia Nacional de Registros Públicos (Sunarp).

El juez a cargo del proceso de interdicción recaba la certificación del registro, a efectos de verificar la existencia del nombramiento. La designación realizada por la propia persona vincula al juez.

Asimismo, la persona adulta mayor puede disponer en qué personas no debe recaer tal designación. También puede establecer el alcance de las facultades que gozará quien sea nombrado como curador."

Si bien es cierto, el proyecto de ley que dio origen finalmente a la modificación normativa citada, consideraba

14 Pues considera que dicho tratamiento lejos de revertir las consecuencias de su enfermedad, no le permitirá (por sus efectos) culminar su vida en el mejor estado posible. 
que cualquier persona mayor de edad (no sólo el adulto mayor) pudiera nombrar su propio curador, quedó finalmente circunscrita a sólo las personas mayores de 60 años.

El Dr. Julio César Barrenechea Gamio, docente universitario y especialista en Derecho de Familia señala, en relación a la limitación de esta facultad sólo para las personas mayores de 60 años, lo siguiente: "Tomando en consideración que no existiría una razón objetiva para que una norma cuyo intrínseco fundamento es precisamente el máximo respeto al principio de la autonomía de la voluntad, circunscriba la misma sólo a personas mayores de sesenta (60) años, hay quienes consideran ya que la citada ley pudiera ser inconstitucional por atentar contra el principio a la igualdad ante la ley." (Barrenechea Gamio, 2013, p. 21)

Para efectos de nuestro artículo, debemos señalar que si bien esta norma es un avance, lo consideramos mínimo, pues ayuda sólo a personas a partir de los 60 años; efectivamente, cumplidos los 60 años, tales personas podrían nombrar a un curador e instruirlo claramente con directivas específicas, pero qué sucedería si antes de dicha edad la persona quedara imposibilitada de poder manifestar una voluntad respecto de su propio cuerpo; nos queda pues un amplio periodo: 42 años (Desde los 18 hasta los 60 años). No entendemos por tanto, el motivo que orilló a nuestros legisladores a colocar dicha limitación.

Otro problema de esta norma es que queda la duda respecto al último párrafo del artículo 568-A, cuando señala que "también puede establecer el alcance de las facultades que gozará quien sea nombrado como curador". Debemos entender con ello, que, además de los temas de índole patrimonial (por ejemplo, la administración de los negocios), ¿podría el curador hacer valer la voluntad establecida por el incapaz que se refiera a directivas sobre su propio cuerpo y que no son de índole patrimonial? ¿Es suficiente esta norma para lidiar con el texto -bastante restringido, bajo nuestro punto de vista-, que contiene el artículo 576 del Código Civil, y que señala que "el curador protege al incapaz, provee en lo posible a su restablecimiento $y$, en caso necesario, a su colocación en un establecimiento adecuado; y lo representa o lo asiste, según el grado de incapacidad, en sus negocios"? Es un tema que deberá aclararse en el futuro, si las iniciativas para la regulación del testamento vital prosperan.

Ahora bien, debemos recalcar un importante trabajo de iniciativa legislativa elaborado, -luego de una profunda investigación sobre el tema-, por la Doctora, Notaria de Lima, Rosalía Mejía Rosasco, quien presenta un proyecto de ley al final de su obra ya citada en este artículo, el cual contiene 5 artículos, debiendo resaltar, para efectos de nuestro trabajo, el artículo 3 , inciso 2, que a la letra dice (Mejía Rosasco, 2009, p. 233-234):

"Artículo 3.- El contenido de las disposiciones de autotutela para la propia incapacidad puede estar referido, entre otros temas, a los siguientes: (...) 2. Disposiciones referidas a la salud del otorgante, tales como los tratamientos médicos, intervenciones quirúrgicas, elección de los profesionales médicos y/o centros de salud de su elección y cualquier otra disposición que conlleve la autorización para aceptar - rechazar la aplicación de medidas terapéuticas, en especial aquellas denominadas de soporte vital".

La iniciativa planteada por la Dra. Mejía, que se plasmaría a través de una Escritura Públi$\mathrm{ca}$, incluye la creación de un Registro de Escrituras Públicas que contenga disposiciones de Autotutela de la Persona Mayor de Edad.

Finalmente, debemos señalar que, ciertamente, nos da mayor tranquilidad que nuestro Tribunal Constitucional venga preocupándose cada vez más por el tema de la autonomía de la voluntad, y se observe importante jurisprudencia en torno al tema ${ }^{15}$, lo que ayudará, sin lugar a dudas, a contar

15 STC Exp. No. 02175-2009-PA/TC, ff.jj. 10 y 11. Publicada en la página web del TC el 19/07/2010 donde el Tribunal señala que..." es necesario el respeto al ejercicio de la autonomía de la voluntad de las partes, las cuales deben ser conformes a los límites que la Constitución y ley hayan previsto". Sentencia citada por el Dr. Ronald Cárdenas Krenz en la ponencia anteriormente citada. 
con un mayor sustento en la oportunidad en que los legisladores prioricen la posibilidad de una regulación de las directivas anticipadas.

Esperamos que en un futuro no lejano, se priorice este tema y se legisle seria y responsablemente por tratarse de una genuina manifestación de la autonomía de la voluntad $y$, por tanto, del legítimo ejercicio de la libertad del ser humano.

\section{Importancia del Testamento VITAL}

Consideramos que permitir la validación o garantía de un testamento vital para que sea ejecutado en la forma como lo desea quien lo otorgó es importante por tres razones fundamentales:

1. Es una garantía de que se está respetando la voluntad autónoma de la persona. El testamento vital o directivas anticipadas son manifestaciones de voluntad que en forma autónoma establece la persona mayor de edad y con capacidad respecto al tratamiento de su cuerpo. No aceptarlas y no ejecutarlas, transgrede la libertad del ser humano violando todos los principios que sustentan la autonomía de la voluntad. ${ }^{16}$

2. El testamento vital puede convertirse en un instrumento muy importante de exoneración de responsabilidad de los profesionales de la salud. En la medida en que el profesional de la salud siga, en estricto, las directivas otorgadas por un paciente en un documento válidamente emitido $\mathrm{y}$ reconocido, podrá hacer frente a eventuales demandas formuladas por los familiares del paciente.

3. Finalmente, consideramos de suma importancia un motivo de tinte humano que aliviará la gran carga que tiene la familia. Cuando un paciente se encuentra imposibilitado de manifestar su voluntad, las decisiones a tomar recaen directamente en los familiares, quienes se cuestionan y hasta existen pugnas respecto a qué se debe hacer y cómo se debe actuar. Todo recae en la simple pregunta -que no siempre tiene una respuesta-: “¿Qué desearía él (refiriéndose al paciente) que hiciéramos?".

El caso emblemático de Terri Schiavo sirve en este momento para ejemplificar nuestra posición. La sentencia de la Corte Suprema que ordenó retirarle la sonda por la cual se le alimentaba basándose en indicios de lo que habría querido Terri, nos da la razón en este punto. Sin la manifestación escrita de Terri, sus padres nunca sabrán si ella hubiera solicitado el retiro de la sonda o, por el contrario, hubiera querido que continuaran luchando. Es posible que esta sentencia haya destrozado a una familia.

Si con este documento (testamento vital) aliviamos, de alguna forma, a la familia en un proceso duro y penoso, contribuiremos a la defensa de la vida humana, pues Familia y Vida Humana están íntimamente vinculadas. Así lo señala Alfonso López Trujillo al decir que "mucho de los graves problemas sobre la vida humana que hoy políticos y legisladores deben considerar tienen su raíz en el deterioro del tejido familiar de las sociedades. Se trata, en realidad, de dos temas profundamente relacionados: familia y vida humana son realidades íntimamente unidas, como son la raíz y el

16 Un caso interesante que suscitó polémica en España en el que se muestra claramente el respeto por la autonomía de la voluntad del paciente fue el siguiente: El hijo de un anciano que padecía una infección en el pie derecho denominado "pie diabético", solicita la autorización judicial para practicar a su padre una intervención quirúrgica para que le sea amputada la pierna hasta la rodilla. La operación era urgente pues la pierna presentaba lesiones gangrenosas y podía expandirse. El enfermo no consentía en la operación y el hijo afirmaba que aquél no tenía en claro su discernimiento. El juez se entrevista con el paciente llegando a la conclusión que obraba con discernimiento al negarse a ser operado. El caso llega a segunda instancia quien señala que al no surgir que la conducta del paciente configurara una forma de suicidio (como lo sustentaba el hijo), debe respetarse la voluntad de aquel y la solución viene impuesta por la naturaleza de los derechos en juego que determinan que el paciente sea el "árbitro único e irremplazable de la situación". El principio expuesto no debe ceder aunque medie amenaza de la vida. El caso sube al Tribunal Supremo quien se encuentra ante la situación de un anciano que veía cercano el fin de su vida, que rechazó someterse a alguna de las terapias costosas y vejatorias y que prefiere morir en paz: así lo permitió el Tribunal, aceptando y respetando la autonomía de su voluntad. 
fruto." (López Trujillo, 2006, p. 20)

Contar con una manifestación del propio paciente, hace más fácil la decisión de la familia en un momento tan triste y delicado por el que deben pasar. Aunque la decisión sea dura, se cuenta con la certeza de que se está actuando en franco respeto de los deseos de su ser querido..."lo importante es garantizar que las decisiones sean las más adecuadas a todos los integrantes de la relación participante, pero en especial acordes a los valores del propio paciente, quien al final tiene la opción de decidir por sí mismo". (García Colorado, Gabriel y otros, 2008, p. 46)

\section{Cómo elaborar un Testa- MENTO VITAL}

El contenido formal de un testamento vital dependerá de la legislación que lo regule, pues para que sea válido y pueda ser ejecutado vía orden judicial si fuera preciso- deberá contener, además de los aspectos de fondo que se refieren a las instrucciones del paciente dentro del límite normativo, una serie de condiciones de tipo formal, dependiendo, reitero, de lo regulado en cada país.

Ahora bien, es importante tener en cuenta algunos aspectos al redactarun testamento vital:

a) La voluntad no debe implicar una acción que vaya en contra del ordenamiento jurídico explícito. Hablamos de autonomía de la voluntad, efectivamente, pero esta autonomía no puede sobrepasar lo permitido por la ley.

Recordemos que en el caso del testamento vital en los países donde no se admite la eutanasia ni ayuda al suicidio, el paciente no solicita morir, tan sólo expresa su deseo de no ser tratado médicamente si su enfermedad es terminal o irreversible. Lo que desea es morir en forma natural (ortotanasia), acepta que la enfermedad ha ganado la batalla, no quiere que alarguen innecesariamente su vida. Lo único que desea es que le apliquen cuidados paliativos, por ejemplo, medicinas para aliviar el dolor. 0 , por otro lado, puede también expresar que desea que se luche con todos los medios necesarios hasta el final, aunque ello implique un encarnizamiento terapéutico.

b) La voluntad no debe implicar una acción médica contra las buenas prácticas establecidas. Se puede limitar la actuación médica; la negativa al tratamiento (aunque sea irracional e incluso vital) es aceptada. Pero no se puede obligar al médico a realizar prácticas no permitidas, como por ejemplo no seguir los llamados protocolos médicos. c) La voluntad del paciente expresada en el documento deberá ser muy clara, pues podría suceder que ante la falta de claridad del paciente, se pretenda (quizá influenciado por algún pariente) aplicar la voluntad de la persona a un caso distinto al acontecido. Se pueden por ejemplo solicitar o no casos concretos y muy específicos como los siguientes:

1. Reanimación cardio-pulmonar: en caso de que ocurra un paro respiratorio o cardíaco.

2. Alimentación artificial por vía intravenosa o por sonda de alimentación.

3. Permanencia prolongada en un respirador (si no se puede respirar por sí solo).

4. Transfusiones de sangre.

A continuación, nos permitimos reproducir tres modelos de testamento vital que servirán de ejemplo para efectos de nuestro trabajo:

\section{Primer Modelo: Con orien- tación y tinte laico: ${ }^{17}$}

“MANIFESTACIÓN DE VOLUNTADES SOBRE EL FINAL DE MI PROPIA VIDA

Yo (nombre y apellidos del testador), con Documento de identidad No.: mayor de edad, con domicilio en: .... y en plenitud de mis facultades mentales, libremente y tras una dilatada meditación,

17 Obtenido de la página de internet: Modelo de la Generalit Cataluyna (España): http://concurso.cnice.mec.es/cnice2006/ material003/Padres/Testamento\%20vital\%20Modelos.htm 


\section{DECLARO:}

Que en el supuesto de encontrarme en unas condiciones en las que no pueda decidir sobre mi atención médica, a raíz de mi deterioro físico y /o mental, por encontrarme en uno de los estados clínicos enumerados en el punto $\mathrm{C}$ de este documento, y si dos médicos autónomos coinciden en que mi fase es irreversible, $\mathrm{mi}$ voluntad incuestionable es la siguiente:

A) Que no se dilate mi vida por medios artificiales, tales como técnicas de soporte vital, fluidos intravenosos, medicamentos o suministro artificial.

B) Que se me suministren los fármacos necesarios para paliar al máximo mi malestar, sufrimiento psíquico y dolor físico causados por la enfermedad o por falta de fluidos o alimentación, aun en el caso de que puedan acortar mi vida.

C) Los estados clínicos a las que hago mención más arriba son:

a. Daño cerebral severo e irreversible.

b. Tumor maligno diseminado en fase avanzada.

c. Enfermedad degenerativa del sistema nervioso $\mathrm{y} / \mathrm{o}$ del sistema muscular en fase avanzada, con importante limitación de mi movilidad y falta de respuesta positiva al tratamiento específico si lo hubiere.

d. Demencias preseniles, seniles o similares. e. Enfermedades o situaciones de gravedad comparable a las anteriores.

D) Designo como $\mathrm{mi}$ representante para que vigile el documento de las instrucciones sobre el final de mi vida expresadas en este documento, y tome las decisiones necesarias para tal fin, a

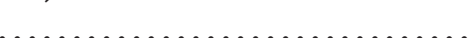

..........., con Documento de Identidad Número:

E) Manifiesto, asimismo, que libero a los médicos que me atiendan de toda responsabilidad civil y penal que pueda derivarse por llevar a cabo los términos de esta declaración.

F) Me reservo el derecho de revocar esta declaración en cualquier momento, en forma oral o escrita.

Fecha:

Firma:

\section{TESTIGOS:}

1. Nombre:

2. Nombre:

Documento de identidad No.: Documento de Identidad No.:

Firma:

Firma:"

2. Segundo Modelo: Con una orientación y tinte religioso:

\section{“MODELO DE TESTAMENTO VITAL DE LA CONFERENCIA EPISCOPAL ESPAÑOLA ${ }^{18}$}

A mi familia, a mi médico, a mi sacerdote, a mi notario:

Si me llega el momento en que no pueda expresar mi voluntad acerca de los tratamientos médicos que se me vayan a aplicar, deseo y pido que esta declaración sea considerada como expresión formal de mi voluntad, asumida de forma consciente, responsable y libre, y que sea respetada como si se tratara de un testamento.

Considero que la vida en este mundo es un don y una bendición de Dios, pero no es el valor supremo y absoluto. Sé que la muerte es inevitable y pone fin a mi existencia terrena, pero creo que me abre el camino a la vida que no se acaba, junto a Dios.

Por ello, yo, el que suscribe, pido que si por mi enfermedad llegara a estar en situación crítica irrecuperable, no se me mantenga en vida por medio de tratamientos desproporcionados; que no se me aplique la eutanasia (ningún acto u omisión que por su naturaleza y en

Se ha excluido exprofesamente de este modelo la cláusula siguiente debido a que no podría consignarse en el caso Peruano por estar prohibida su ejecución tomando en cuenta lo ya comentado en el punto IV del presente artículo (artículos 112 y 113 de nuestra legislación penal): “C) Que, si me hallo en un estado particularmente deteriorado, se me administren los fármacos necesarios para acabar definitivamente, y de forma rápida e indolora, con los padecimientos expresados en el punto (B) de este documento".

18 Modelo obtenido de: http://www.conferenciaepiscopal.es/index.php/testamento-vital.html (Página de la Conferencia Episcopal Española). 
su intención me cause la muerte) y que se me administren los tratamientos adecuados para paliar los sufrimientos.

Pido igualmente ayuda para asumir cristiana y humanamente mi propia muerte. Deseo poder prepararme para este acontecimiento en paz, con la compañía de mis seres queridos y el consuelo de mi fe cristiana, también por medio de los sacramentos.

Suscribo esta declaración después de una madura reflexión. $Y$ pido que los que tengáis que cuidarme respetéis mi voluntad. Designo para velar por el cumplimiento de esta voluntad, cuando yo mismo no pueda hacerlo, a........................

Faculto a esta misma persona para que, en este supuesto, pueda tomar en mi nombre, las decisiones pertinentes. Para atenuaros cualquier posible sentimiento de culpa, he redactado y firmo esta declaración.

Nombre y apellidos:

Firma:

Lugar y fecha:"

3. Modelo elaborado por la Asociación de Abogados Cristianos 19 :

“A mi familia, a mi médico y a mi notario:

Si me llega el momento en que no pueda expresar mi volun- tad acerca de los tratamientos médicos que se me vayan a aplicar, deseo y pido que esta declaración sea considerada como expresión formal de mi voluntad, asumida de forma consciente, responsable y libre, y que sea respetada como si se tratara de un testamento.

Yo,

pido que se respete mi vida y se proteja hasta el último momento, tal y como lo consagra la Constitución Española, pido que no se me aplique la eutanasia activa, ni la pasiva y que se me administren los tratamientos adecuados para paliar los sufrimientos y alimentación e hidratación necesarias para mantenerme con vida.

Pido igualmente ayuda para asumir cristiana y humanamente mi propia muerte. Deseo poder prepararme para este acontecimiento en paz, con la compañía de mis seres queridos y el consuelo de mi fe cristiana.

Asimismo solicito, que esta voluntad que expongo aquí, y que es la propia del que suscribe, no pueda ser tergiversada, alterada y/o modificada por ninguna persona ni profesional, habida cuenta que en el momento presente el que expone, es plenamente capaz, de hecho y de derecho, y tiene el expreso deseo de prever su futuro y de que se respete su voluntad.

Suscribo esta declaración después de una madura reflexión.
Y pido que los que tengáis que cuidarme respetéis mi voluntad. Soy consciente de que os pido una grave y difícil responsabilidad. Precisamente para compartirla con vosotros y para atenuaros cualquier posible sentimiento de culpa, he redactado y firmo esta Declaración, para que se inscriba en el Registro de Voluntades que corresponda y en cualquier caso se respete como voluntad clara y definitiva.

Firma:

Fecha:"

\section{Reflexiones Finales}

1) Debemos considerar la real posibilidad de impulsar la regulación -en nuestro paísde las directrices anticipadas a fin de garantizar de una manera más completa el respeto por la autonomía de la persona.

2) La aceptación en nuestra legislación del derecho al consentimiento informado nos da la esperanza de que se pueda aplicar el principio: "a misma razón, mismo derecho", es decir, el deseo porque se respete la voluntad del paciente respecto de su cuerpo en la actualidad o en el futuro. La única diferencia es el momento en el tiempo.

3) Las escasas normas que hoy en día regulan parcialmente el tema de la autotutela, no son garantía, en forma alguna, del respeto a la voluntad de la persona; son en

19 Este modelo se elaboró luego de la muerte de la ciudadana española Ramona Estévez; fue el primer caso de retiro de alimentación en contra del criterio de los médicos, por indicación de la Junta de Andalucía. Dicho modelo incluye la petición de que se mantenga la nutrición e hidratación necesarias hasta el momento de la muerte natural, petición que se va de la mano con la ética médica y defiende al paciente inconsciente de eventuales abusos. Ver: http://www.vida-digna. org/\#!testamento-vital/cqzn. 
algunos casos muy limitativos y en otras muy amplias, lo que implica la existencia -en la práctica- de peligrosas puertas abiertas que no garantizan el citado respeto.

4) Debemos considerar que las directivas anticipadas se constituyen en un importante instrumento de protección para el profesional de la salud, quien es el llamado a efectuar o dejar de efectuar los tratamientos médicos necesarios. Consideremos que el profesional de la salud tiene, constantemente sobre él, una suerte de "espada de Damocles" pudiendo en algún momento ser demandado por sus acciones.

5) Además de constituirse en un instrumento de protección para el profesional de la salud, se yergue también como un mecanismo de ayuda, de apoyo a la familia. Aliviará la conciencia de la familia evitando la eterna duda: “iHicimos bien o no? ¿Hicimos lo que él o ella hubiera querido o no?".

6) Hasta que la normatividad no sea aprobada, sería aconsejable difundir la idea de que los familiares más cercanos conozcan -a ciencia cierta- las voluntades de sus seres queridos sobre estos temas. Tener un documento privado manifestando dicha voluntad, serviría, en todo caso, para que los familiares o médicos pudieran tener un acercamiento a esa voluntad en caso de situaciones extremas.

\section{Referencias Bibliográficas}

Abellan Sallort, José Carlos (2008). "Eutanasia y Ortotanasia: El problema de la autonomía en el Derecho Español". En: Temas de Bioética y Derecho. Lima: Universidad Femenina del Sagrado Corazón-Cátedra UNESCO de Bioética y Biojurídica y Editorial Grandez Gráficos SAC.

Arbe Ochandino, Milagros (2011). Estudio de las instrucciones previas en el ámbito sanitario a través del ordenamiento jurídico español. Salamanca: Ediciones Universidad de Salamanca.

Barrenechea Gamio, Julio César (2013). "Proyectando la voluntad hacia el momento en que uno ya no pueda tomar decisiones: la facultad de designar curador para sí mismo". En: Lumen, Revista de la Facultad de Derecho de la Universidad Femenina del Sagrado Corazón, No. 9. Lima: Editorial GRAFIMAG SRL.

Bermejo José Carlos y Rosa María Belda (2006). Bioética y Acción Social. Cómo enfrentar los conflictos éticos en la intervención social. Santander: Editorial SAL TERRAR.

Cárdenas Krenz, Ronald (2015). Ponencia “¿Qué tan autónoma es la autonomía de la voluntad? Consideraciones a partir de algunas interesantes sentencias del Tribunal Constitucional peruano". Córdoba-Argentina (inédita).
Durante, Vincenzo (2012) “Directivas anticipadas y nombramiento judicial de tutela limitada (administrazione di sostengo) en Italia". En: Revista de Derecho de la Familia y de las Personas. Buenos Aires: Editorial La Ley.

García Colorado, Gabriel y otros (2008). Bioética y muerte. Aspectos Sociales y éticos. México: Editorial Trillas.

López Trujillo, Alfonso (2006). Temas candentes de Bioética y Familia. Madrid: Editorial Palabra.

Mejía Rosasco, Rosalía (2009). Estipulaciones de autotutela para la propia incapacidad: la penúltima voluntad. Lima: Editorial Grijley.

Osada Liy, Jorge (2009) “Alzheimer: manejo y tratamiento". En: Revista de la Facultad de Psicología de la UNIFE: "Alzheimer y otras demencias". Lima: Ediciones Libro Amigo.

Pfeiffer, María Luisa. (2008) "Decisiones al final de la vida". En: Revista de Medicina y Bioética. Argentina: Editorial Quirón.

Torres Morales, Sylvia Amelia (2008). "La Eutanasia y la Iglesia Católica". En: Boletín del Instituto de la Familia de la UNIFE No. 10. Lima: Facultad de Derecho de la Universidad Femenina del Sagrado Corazón.

Wagner Grau, Patrick. Entrevista "No se puede jugar a ser Dios". Diario El Comercio 10 de abril del año 2015. 


\section{Otros materiales} CONSULTADOS:

- Código Civil Peruano de 1984.

- Código Penal Peruano de 1991.
- Catecismo de la Iglesia Católica. 1992.

- Ley General de Salud, 26842.

- Ley No.29633 que permite a la persona mayor de 60 años autodesignarse a un curador.
- Ley 41/2002: Ley española de Autonomía del Paciente. 